\begin{tabular}{|c|c|c|}
\hline \multirow{2}{*}{ IDUNAS } & NATURAL \& APPLIED SCIENCES & 2020 \\
& Vol. 3 \\
No.1 \\
$(28-39)$
\end{tabular}

\title{
Viability and Morphology of Human Dental Pulp Stem Cells in The Presence of Citrus Pectin
}

\author{
Research Article \\ Gamze Ayar $^{1}$ (D), Merve Çapkın Yurtsever ${ }^{* *}$ (D) \\ ${ }^{1}$ Adana Alparslan Türkeş Science and Technology University, Faculty of Engineering, Department of Bioengineering, Adana, Turkey \\ Author E-mails \\ mcyurtsever@atu.edu.tr \\ Correspondence to: M. Çapkın Yurtsever, Adana Alparslan Türkeş Science and Technology University, \\ Faculty of Engineering, Department of Bioengineering, Adana/Turkey \\ DOI: 10.38061/idunas.745983
}

Received: May 31, 2020; Accepted: June 25, 2020

\section{Abstract}

Pectin is a galacturonic acid rich heteropolysaccharide which regulates plant cell metabolism. Plenty of fresh fruits and fruit pomaces from fruit juice production can be used as a raw material in commercial pectin production. Pectin occupies a large global market size especially in food industry and the utilization of waste materials for obtaining pectin molecules as a high value-added product makes it very favorite industrial material. Besides food industry, pectin is gaining attention in tissue engineering and drug development studies. In this study, the effects of citrus pectin on viability and morphology of human dental pulp stem cell (hDPSC) were investigated. The cells were cultured in the presence of pectin in culture medium $(0.43,0.85$ and $1.7 \mathrm{mg} / \mathrm{mL})$ for eight days. Resazurin application and MTT assay were applied on day one and eight for cellular viability. Cellular morphology was investigated by invert phase contrast microscope, live/dead cell staining and F-actin/nucleus immunofluorescence staining. MTT analysis results indicated that the viability of hDPSCs decreased significantly due to dissolved pectin in culture medium at applied concentrations. There was no significant morphological difference in the cells under invert phase contrast microscope and no significant staining difference in live/dead cell staining images. On the other hand, F-actin/nucleus staining showed that there were some condensed and crescent cell nuclei in the pectin applied groups when compared to the control groups which may be related to apoptosis. In conclusion, the viability of hDPSCs decreased and crescent cell nuclei formation was observed due to the presence of citrus pectin in the cell culture medium.

Keywords: Pectin, Human Dental Pulp, Mesenchymal Stem Cell

\section{INTRODUCTION}

Pectin is a complex plant cell wall polysaccharide which is responsible for cell growth, differentiation and defense mechanism. Pectins, as a biomacromolecule, mainly consist of galactronic acid and rhamnogalacturanon I and substituted by rhamnogalacturonan II (RG-II), and xylogalacturonan (XGA) $[1,2]$. They are divided in two groups according to the degree of esterification. High methoxy (HM) pectins 
have esterification degrees above 50\% and and low methoxy (LM) pectins have esterification degrees below $50 \%[3-5]$.

Pectin is a widely used stabilizer and gelling agent in food industry and has expanding market share in cosmetics and pharmaceuticals [6]. It is obtained from various sources as citrus peel (85\%), apple, sour cherry pomace and black cherry tomato [7-11]. The main pectin extraction method is based on acid hydrolysis in hot water [1]. There are some examples for different types of pectin extractions: pectin extraction from grapefruit (Citrus paradisi Macf.) peel with array-induced voltage approach [12], pectin extraction from walnut processing waste with ultrasound-assist, high-viscosity apple peel pectin extraction with citric acid [13], pectin and phenolic compounds from sour cherry pomace (SCP) with microwaveassisted approach [9] and also pectin extraction from orange peel by a combination of surfactant and microwave-assisted extraction methods [14]. Especially pectin extraction from the apple pomace is easily processible and safely utilized in industrial processes and also eco-friendly method $[3,4]$.

The effects of dietary pectin or modified citrus pectin have been studied in the literature and it was concluded that pectin rich diet can reduce blood cholesterol, supports immune system and decreases tumorigenic activity [15-17]. In a study, increased number of surviving stem cells in intestine of mice which were fed with pectin rich diet and exposed to total-body gamma-IR was showed. This result indicates a radioprotective property of dietary citrus pectin [18]. Pectin extracted from cacao pod husks after deacetylation and de-esterification processes provides antitumoral activity [19]. The anti-tumorigenic activity of modified citrus pectin is generally related with its galectin-3 antagonism which is a member of lectin family and plays an important role in cancer and development of fibrotic disease [20]. Cancer stem cells are an important subgroup of cancer cells in tumor tissues. They exhibit increased resistance to drug molecules and other cancer treatment strategies. Their chemoresistance is mainly because of high expression of multi drug resistance proteins such as ABC transporters [21-23]. In addition, increased expression of galectin-3, is related to cancer development and metastasis, in tumor cells [24, 25] and cancer stem cells are shown in the studies [26]. There are some therapeutic strategies for inhibition of cancer stem cells including monoclonal antibodies and micro RNA technologies [23] and different types of pectin molecules may help the inhibition of cellular activity.

For tissue engineering applications pectin, is generally used in combination with other materials such as chitosan, hydroxyapatite, poly-L-lactone, and gelatin to increase its mechanical properties in the fabrication of 3D hydrogels [27, 28]. Pectin containing injectable biomaterials [29] and 3D matrices which supports cell attachment and proliferation can also be prepared by electrospinning process [30, 31]. In a study, vascular cell differentiation of mesenchymal stem cells (MSCs) was investigated on electrospun pectin hydrogel nanofibers. The cells were able to retain their viability for 14 days on the hydrogel nanofibers and their differentiation was changed with the stiffness of the hydrogels and was triggered in the direction of vascular cells [32].

Human body possesses limited regenerative capacity in organ or tissue repair, e.g. in pathologic conditions or in degenerative diseases. Regenerative medicine field highlights the function of stem cells for tissue repair and regeneration of organs because of their unique properties such as self-renewal, proliferation and differentiation into desired and various cell types $[33,34]$. Mesenchymal stem cells are found almost in every tissue in our body such as, dental pulp, craniofacial bone, dental follicle, tooth germ, apical papilla, oral mucosa, gingiva, bone marrow, adipose tissue and periosteum [35-38]. The effects of pectin biomacromolecule on behavior of MSCs have been investigated. In a study, human amniotic membrane MSCs were cultured in hydroxyapatite/LM pectin composite gel structure. It was shown that MSCs preserved their osteogenic differentiation capacity and inhibition of $\mathrm{T}$ cell proliferation in the presence of LM pectin, also they did not trigger immune response [39]. Pectin/chitosan membrane can provide attachment, adhesion and proliferation of adipose-derived stem cells (ADSCs) [40]. Moreover, bone shaft 
MSCs on chitosan/gelatin/pectin network (CGP) films exhibit high ALP activity, osteogenic gene expression and increased mineral formation capacity due to the suitable physicochemical and mechanical features of CGP network films. These results indicate that the network film has the potential to control the MSCs fate [28]. In another study, the biocompatibility of vancomycin hydrochloride including poly (Llactide) fibers loaded silk fibroin/oxidized pectin hydrogels was shown by MTT assay. Human adipose tissue derived MSCs preserved their viability for eight day cell culture study [41].

Dental pulp stem cells (DSCs) are post-natal stem cell group which have similar properties to MSC with their self-renewal capacity, high proliferation rate and multilineage differentiation potential [42]. Dental pulp SCs can be isolated from third molars and dedicious teeth (DPSCs) without any invasive surgical process, so that they are a promising group of SC with their ease of obtain. Therefore, DPSCs are valuable and crucial MSC sources for tissue engineering and regenerative medicine studies [43]. Dental pulp stem cells involve neural crest stem cells and they have potential to differentiate into neurogenic, adipogenic, chondrogenic, osteogenic cell types [44, 45]. The studies which include pectin biomolecule and MSC interaction is generally based on bioscaffolds. Pectin as a part of biomaterial or as a soluble agent may trigger different signaling pathways in MSCs. To the best of our knowledge, there is no study in which the effects of the presence of soluble pectin in cell culture medium on human mesenchymal stem cells were investigated. In this study, it was aimed to investigate the effects of dissolved citrus pectin in culture medium on human dental pulp stem cells viability and morphology.

\section{MATERIALS AND METHODS}

\section{Human Dental Pulp Stem Cells Culture}

Human dental pulp stem cells (hDPSCs) which were isolated and characterized in a previous study [39] were a kind gift from Prof. Dr. Menemşe Gümüşderelioğlu, from Hacettepe University, Turkey. The cells were cultured in 15\% (v/v) fetal bovine serum (FBS, Biowest, France) including alpha-Minimum Essential Medium ( $\alpha$-MEM, Biochrom, Germany). The antibiotics were used as $[10 \mathrm{units} / \mathrm{mL}$ penicillin and $10 \mu \mathrm{g} / \mathrm{mL}$ streptomycin (Sigma, Germany), $50 \mu \mathrm{g} / \mathrm{mL}$ gentamicin (Sigma, Germany) and $0.25 \mu \mathrm{g} / \mathrm{mL}$ Amphotericin B (Sigma, Germany)] at $37^{\circ} \mathrm{C}$ in $5 \% \mathrm{CO} 2$ atmosphere (Heraus, Germany). The cells were detached from the surface by trypsinization at $80 \%$ confluency and cryopreserved for further studies. Human DPSCs at passage 5 and 6 were used in the studies.

\section{Pectin Solution Preparation}

Stock pectin (Galacturonic acid $\geq 74.0 \%$, Sigma Aldrich) solution was first prepared by dissolving $50 \mathrm{mg}$ citrus pectin in $250 \mu \mathrm{l}$ absolute ethanol [7]. After complete dissolution the mixture was added into $4750 \mu \mathrm{l} \alpha$-MEM medium and was filtered through $0.22 \mu \mathrm{m}$ syringe filter. After filtration, corresponding reagents were added to this solution to obtain $15 \%$ FBS (v/v), $1 \%(\mathrm{v} / \mathrm{v})$ L-glutamin and $1 \%(\mathrm{v} / \mathrm{v})$ antibiotic mixture in the final stock solution with $8.5 \mathrm{mg} / \mathrm{mL}$ pectin concentration.

\section{Cell Viability Assays: Resazurin Application and MTT Assay}

Human DPSCs were cultured on 24 well plates as $10 \times 10^{3}$ cells $/ \mathrm{cm}^{2}$ in culture medium before application of pectin solution. After 24 hours, the culture media of the cells were changed with the fresh culture medium for cell control group, with pectin including media $(0.43,0.85$ and $1.7 \mathrm{mg} / \mathrm{mL})$ for sample groups and ethanol including medium $(0.85 \%, \mathrm{v} / \mathrm{v})$ for negative control group. Pectin concentrations were selected within the range of investigated concentrations according to the literature [7, 46, 47]. The cells were incubated in these media for eight days at $37^{\circ} \mathrm{C}$ in $5 \% \mathrm{CO}_{2}$ atmosphere.

Resazurin stock solution (Sigma, Germany) was prepared as $0.8 \mathrm{mM}$ in $\mathrm{Ca}+2 \mathrm{Mg}+2$ containing PBS (Biowest, France, PBS+). The solution was filtered through $0.22 \mu \mathrm{m}$ syringe filter and kept at $+4 \mathrm{o} \mathrm{C}$ during 
experiments. This stock solution was diluted by culture medium just before the application to the cells. The used medium on the cells were aspirated and fresh resazurin working solution (1/10 dilution in culture medium) was applied to the wells. The color change of the medium was observed after 4 hours at days one and eight. Due to the non-toxicity of resazurin on the cells, the used resazurin containing medium was collected for analysis after application. Cells were washed with PBS+ and fresh positive-negative control and pectin including media were applied to the cells. The cells were examined under inverted microscope (Leica, DM IL Led Fluo, Germany).

MTT analysis was carried out at the end of the culture period, at day 8. MTT working solution was prepared by 10 times dilution of $2.5 \mathrm{mg} / \mathrm{mL}$ MTT stock solution (Biofroxx, Germany) with culture medium without serum. Used culture media were aspirated from the wells and $600 \mu \mathrm{L}$ MTT working solutions were applied to the cells. The cells were incubated with MTT working solution for 4 hours at $37{ }^{\circ} \mathrm{C}$ in $5 \% \mathrm{CO} 2$ atmosphere. At the end of incubation, used MTT solutions were withdrawn and $0.04 \mathrm{M} \mathrm{HCl} \mathrm{containing}$ isopropanol solution was applied to the wells to dissolve newly formed formazan crystals which are indication of mitochondrial activity of viable cells. The corresponding MTT absorbance values were recorded by UV-Vis Spectrophotometer (Agilent Cary 60) at $570 \mathrm{~nm}$ in comparison with $690 \mathrm{~nm}$ reference wavelength. Cell viability (\%) was expressed in relation to the absorbance value of solvent control cells.

\section{Live/Dead Cell Imaging}

To assess the live/dead hDPSCs after pectin solution application, Ethidium Homodimer-1 (0.01 M, Eth-1, Abcam, UK) and Calcein AM (0.01 M, Sigma, Germany) dyes were used. Each dye was added into $1 \%$ L-glutamin containing PBS+ in $1 / 1000$ dilution to obtain live/dead cell staining solution. Cells were washed once with PBS+ and live/dead cell staining solution was applied for $30 \mathrm{~min}$ at room temperature in dark. At the end of incubation period, staining solution was aspirated and the cells were washed once with PBS+ and visualized in PBS+ under a fluorescence microscope (Leica, DM IL Led Fluo, Germany) immediately.

\section{F-actin/Nucleus staining}

To observe the cellular cytoskeleton and cell nucleus, F-actin/nucleus staining was carried out. The cells were washed with PBS once and fixed in $4 \%$ formaldehyde (v/v in water) solution for 20 minutes at room temperature. After removal of the fixation solution, the cells were washed with PBS and $0.1 \%$ Triton X-100 solution in PBS was applied for $8 \mathrm{~min}$ to ensure cell membrane permeability. Dye solution was prepared in PBS containing 1\% BSA (Bovine Serum Albumin, PBSA) with $2 \mu \mathrm{L} / \mathrm{mL}$ Phalloidin-iFluor 488 Reagent (Anti-Factin antibody, Abcam, UK) and $1 \mu \mathrm{g} / \mathrm{mL}$ DAPI (Sigma, Germany). After membrane permeability step, the cells were washed with PBSA and they were incubated in dye solution for 90 minutes at room temperature in dark. The cells were washed with PBSA for two times to remove unbound reagents and glycerol solution was added on the cells. The images of immunostained cells were taken under fluorescent microscope

\section{Statistical Analysis}

Statistical analysis was performed by one-way ANOVA and Post-hoc Tukey test by GraphPad Prism 8 statistic software program (GraphPad Software, USA).

\section{RESULTS AND DISCUSSION}

In this study, the effects of dissolved citrus pectin biomacromolecule on human dental pulp stem cells were investigated by means of cell viability and morphological analyses. 
Resazurin sodium salt or resazurin including dye application is widely used for animal, yeast, bacteria and plant cells [48]. It is a non-toxic dye and the cells do not die after application; thus, it allows to track the viability of the same cell group during cell culture studies. The viability of MSCs also has been followed by resazurin dye in our previous studies [49]. In this study, the viability of hDPSCs was investigated by the application of $80 \mu \mathrm{M}$ resazurin sodium salt solution. Mitochondrial activity in both control groups (ethanol group as a solvent control group and cell control group without any reagent application) and pectin applied groups were observed by the color change of culture media from light blue to purple and pink. There was no color difference between the groups on days one and eight according to our visual observations (data not given). Another assay which was carried out for the quantification of viability results of the same cell groups was MTT assay (Fig. 1). It was applied on day 8 and the results given in Fig. 1 were calculated by normalizing the corresponding absorbance values with respect to the absorbance values of solvent control group. It was clearly seen that, dissolved pectin application significantly decreased hDSCs viability when compared to the viabilities of control groups. The most decreased viability was observed in $1.7 \mathrm{mg} / \mathrm{mL}$ pectin applied group when compared to the control groups. In a study, the effect of citrus pectin and heat modified citrus pectin $(3 \mathrm{mg} / \mathrm{mL})$ in cell culture medium on HepG2 (liver) and A549 (lung) human cancer cell lines was investigated. It was concluded that both pectin types decreased cellular viability and some caspase independent cell death signals were observed in A549 cells [50]. In another study, viability of HaCaT (human keratinocyte) cell line in the presence of high molecular weight citrus pectin and modified citrus pectin with low molecular weight and low degree of esterification was investigated. It was stated that both type of pectin decreased cell viability in the 1-750 $\mu \mathrm{g} / \mathrm{mL}$ concentration range [51].

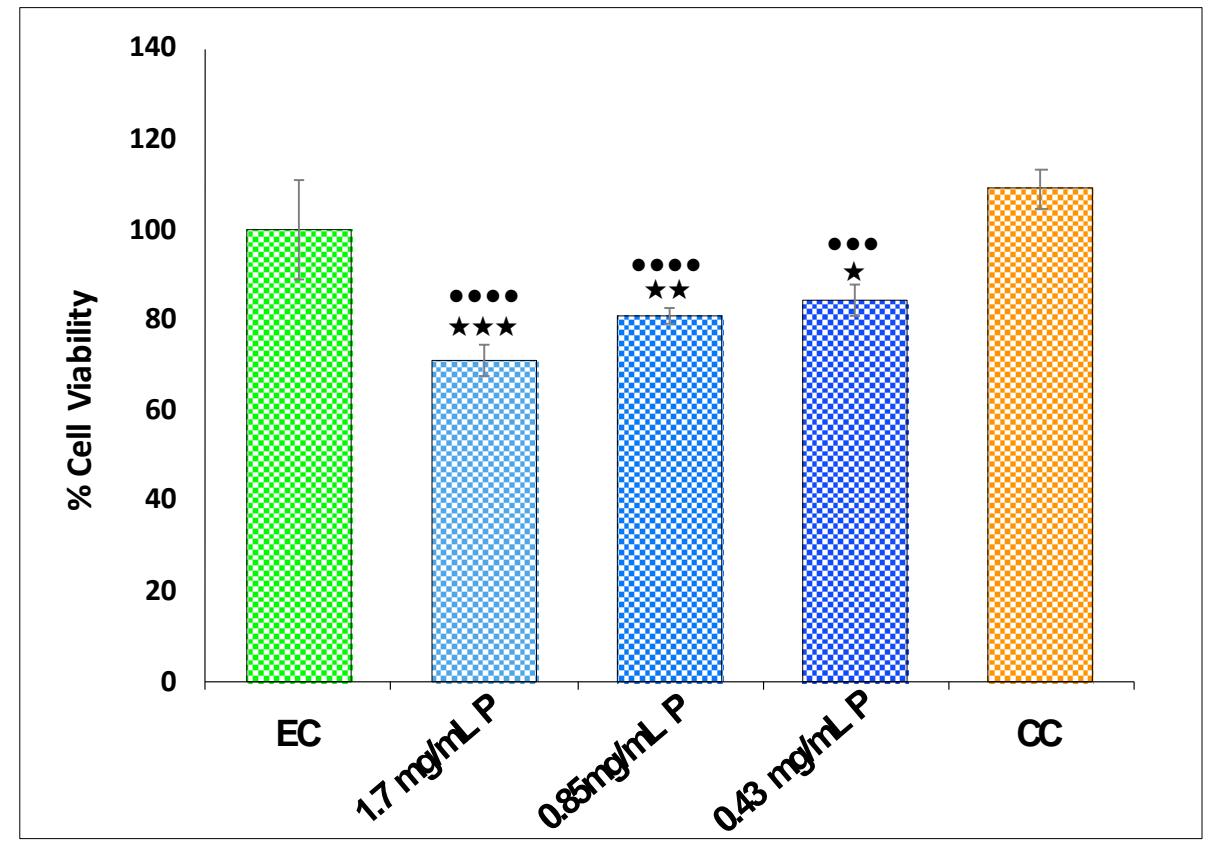

Figure 1. Viability of hDPSCs (\%) by MTT assay on day eight. The absorbance values were normalized with respect to the absorbance values of ethanol applied group. P: Pectin, EC: Ethanol control, CC: Cell control " $\star$ ” represents the significant difference in comparison with EC and "•" represents the significant difference in comparison with $\mathrm{CC}(\mathrm{p}<0.05 \star ; \mathrm{p}<0.01 \star \star ; \mathrm{p}<0.001 \star \star \star, \bullet \bullet \bullet ; \mathrm{p}<0.0001 \bullet \bullet \bullet \bullet)$.

Inverted phase contrast images of hDPSCs were given in Fig 2. The morphologies of the cells in every group were as expected from MSCs with thin, bipolar, fibroblastic features (on day 1). After 8-day cell culture, the proliferation of the cells was significantly high, and it was not possible to analyze single cell morphology. However, their high proliferative behavior and growing capacity in multilayers were clearly observed in every group. As a result, there was not any significant change in the cell morphology which 
can be related to decreasing cellular activity. Calcein-AM and Ethidium homodimer-1 staining allows visualization of live and death cells at the same time in live cell culture (Fig. 3). Non-fluorescent calceinAM is a healthy cell membrane permeable die and turns into fluorescent calcein after intracellular esterase activity. Eth-1 is a nucleic acid binding reagent which allows visualization of cells with membrane damage (necrotic cells) shown in red color. Most of the cells were alive staining in green color and there were a few red points indicating death cells in the culture. Hence, decreasing mitochondrial activity may be a result of suppressed proliferation instead of activated necrotic cell death.

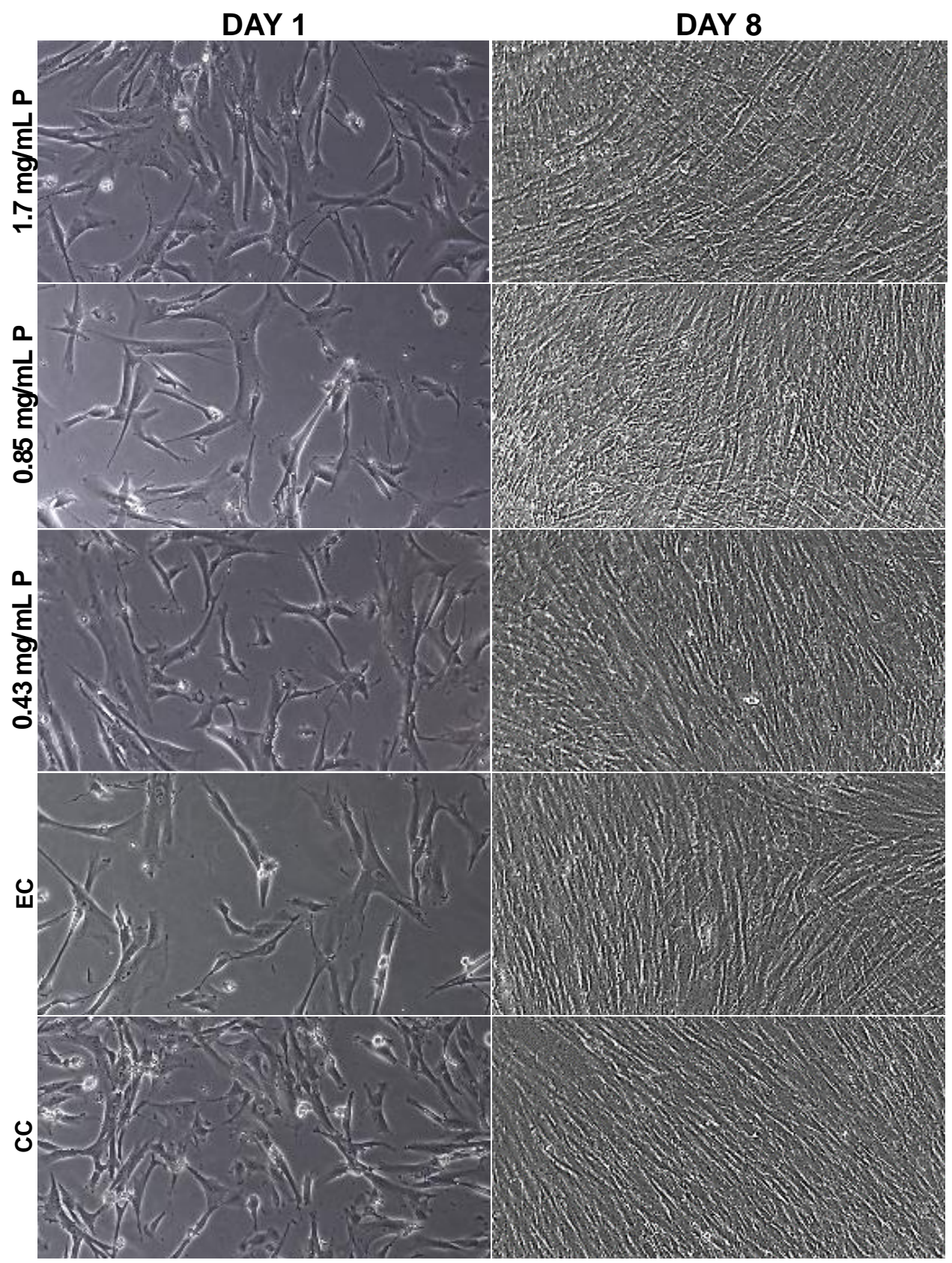

Figure 2. Phase contrast images (20X) of hDPSCs on days 1 and 8 before resazurin application under inverted phase contrast microscope. P: Pectin, EC: Ethanol control, CC: Cell control.

Mesenchymal stem cells spread on the surface and organize their filamentous actin stress fibers. In this study, F-actin/nucleus staining showed that hDPSCs fibrous actin filaments were organized in all groups, however, the difference in the morphology of the nuclei of certain cells in the pectin applied groups 
was shown by arrows in Fig. 3. Condensed and crescent nuclei was shown in the cells which can be a sign of early stages of apoptotic cell death [52]. Induction of apoptotic pathways in cancer cells in the presence of different types of pectin has been discussed in many studies [53-55]. In a study, autophagy was also observed in A549 cells after heat-modified citrus pectin application in culture medium [50]. Hence, the crescent nuclear shape in hDPSCs of this study may be a sign of apoptotic cell death induced by the presence of pectin in culture medium which can be further validated by apoptotic markers and molecular studies. The effects of the presence of pectin in the $0.1-10 \mathrm{mg} / \mathrm{mL}$ concentration range were investigated in cancer cells related research in the literature [7, 46, 47]. In this study, $0.43-1.7 \mathrm{mg} / \mathrm{mL}$ pectin concentration range was selected in order to be comparable with the results in literature studies. However, higher pectin concentrations, longer cell culture periods and different types of pectin molecules should be investigated to observe more significant and specific changes in the viability, morphology and molecular signaling pathways of hDPSCs.

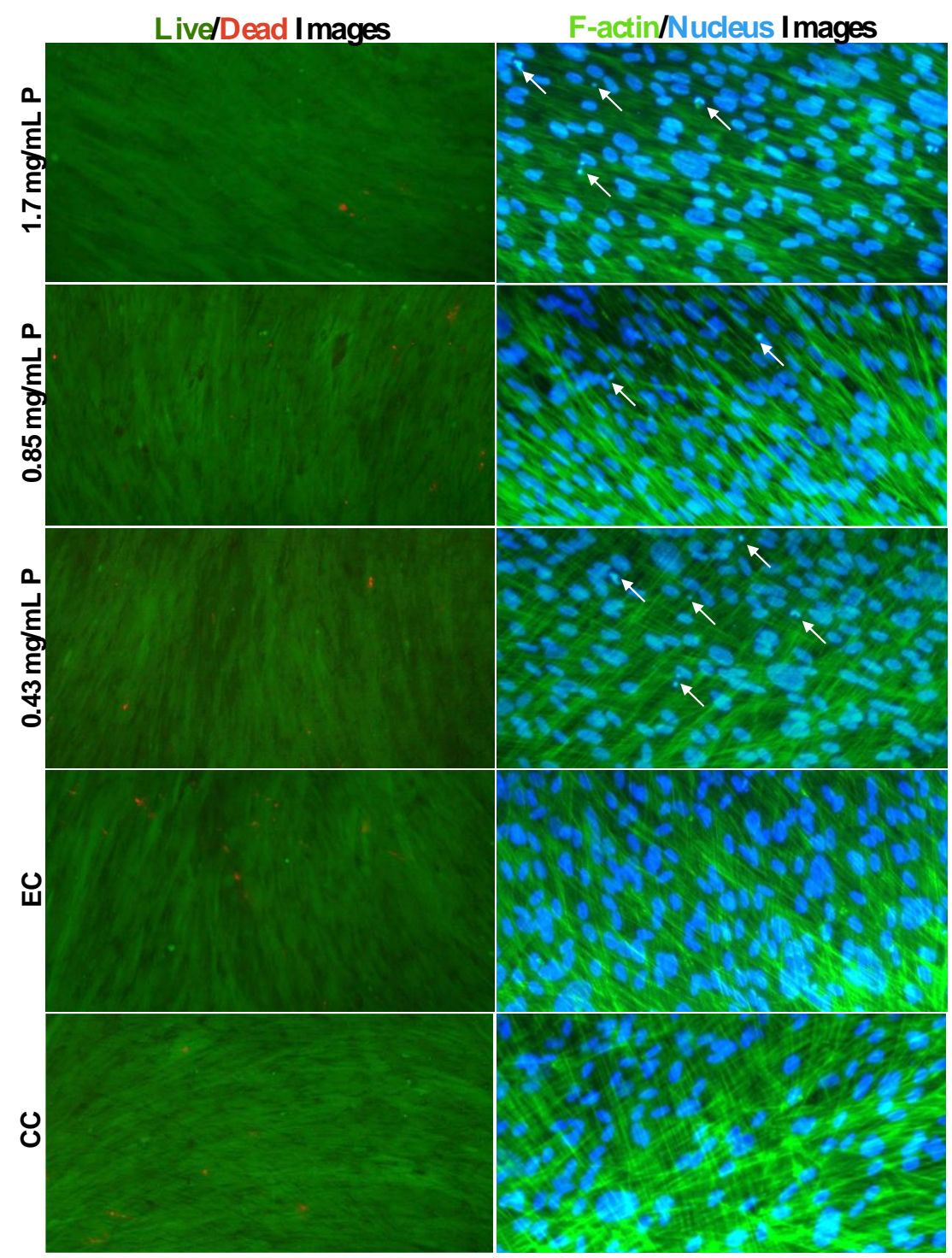

Figure 3. Fluorescence images of hDPSc on day eight. Live/dead cell analysis was performed at the end of culture using Calcein-AM for living cells and Ethidium homodimer-1 (Eth-1) for dead cells (10X). Calcein-AM incorporated living cells stained green color and Eth-1 permeable dead cells stained in red color. F-actin and nucleus staining was performed after fixation to analyze cell morphology (20X). Green color shows iFluor 488 conjugated anti F-actin antibody stained filamentous actin fibers, while blue color shows DAPI stained cell nucleus. White arrows show condensed and crescent cell nuclei. P: Pectin, EC: Ethanol control, CC: Cell control. 
In this study, the decrease in the viability of hDPSCs may be explained by the interaction of pectin and galectin-3. Galectin-3 as a sub-group of carbohydrate binding galectin family is responsible for cell adhesion, proliferation, survival, tumor cell proliferation and metastasis [25]. It is also expressed in MSCs and can affect immunomodulatory properties of these cells [56]. The inhibition of galectin-3 related signaling pathways such as cell adhesion, survival and proliferation in the presence of different types of pectin were shown in the studies $[53,57]$. Galectin-3 binding activity of $\mathrm{pH}$ modified citrus pectin was also clearly shown by enzyme linked immunosorbent assay [53] and suitability of some types of assays were studied [58]. Galectin-3 expression in cancer stem cells was also shown in a study [26] but it is a new research area and there are many points waiting to be clarified on this subject. Investigation of the interactions between cancer stem cells, galectin-3 and different types of pectin molecules will contribute to the development of alternative treatment strategies for cancer disease.

\section{CONCLUSIONS}

In this study, the effects of citrus pectin on human dental pulp stem cell viability and morphology were investigated. It was observed that proliferation of hDPSCs significantly decreased due to the presence of pectin in the cell culture medium for the selected concentration range. In addition, the shape of the nuclei of pectin applied cells showed crescent morphology when compared to the ellipsoid and smooth shape of nuclei in the control cells. This crescent morphology of nucleus may be a sign of apoptotic cell death induction by the presence of citrus pectin. It can be concluded that pectin biomacromolecule can significantly affect the viability and morphology of hDPSCs. Based on this information, it can be suggested that the evaluation of the effects of the pectin molecule on cancer stem cells may also be important.

\section{ACKNOWLEDGEMENT}

This project was supported by The Scientific and Technological Research Council of Turkey, 2209A - Research Project Support Programme for Undergraduate Students, 1919B011803760.

\section{REFERENCES}

[1] D. Mohnen, "Pectin structure and biosynthesis," Curr Opin Plant Biol, vol. 11, no. 3, pp. 266-77, Jun 2008, doi:

10.1016/j.pbi.2008.03.006.

[2] A. G. J. Voragen, G.-J. Coenen, R. P. Verhoef, and H. A. Schols, "Pectin, a versatile polysaccharide present in plant cell walls," Structural Chemistry, vol. 20, no. 2, p. 263, 2009/03/13 2009, doi: 10.1007/s11224-009-9442-

$\mathrm{Z}$.

[3] F. Capel, T. Nicolai, D. Durand, P. Boulenguer, and V. Langendorff, "Calcium and acid induced gelation of (amidated) low methoxyl pectin," Food Hydrocolloids, vol. 20, no. 6, pp.
901-907, 2006, doi:

10.1016/j.foodhyd.2005.09.004.

[4] P. Sriamornsak, "Chemistry of pectin and its pharmaceutical uses: A review," Silpakorn University International Journal, vol. 3, pp. 206228, 01/01 2003.

[5] W. G. T. Willats, J. P. Knox, and J. D. Mikkelsen, "Pectin: new insights into an old polymer are starting to gel," Trends in Food Science \& Technology, vol. 17, no. 3, pp. 97-104, 2006, doi: 10.1016/j.tifs.2005.10.008.

[6] M. Pagliaro, R. Ciriminna, A. Fidalgo, R. Delisi, and L. Ilharco, "Pectin Production and Global Market," Agro Food Industry Hi Tech, vol. 27, 09/15 2016. 
[7] L. Delphi and H. Sepehri, "Apple pectin: A natural source for cancer suppression in 4T1 breast cancer cells in vitro and express p53 in mouse bearing 4T1 cancer tumors, in vivo," Biomed Pharmacother, vol. 84, pp. 637-644, Dec 2016, doi: 10.1016/j.biopha.2016.09.080.

[8] M. Bergman, M. Djaldetti, H. Salman, and H. Bessler, "Effect of citrus pectin on malignant cell proliferation," Biomed Pharmacother, vol. 64, no. 1, pp. 44-7, Jan 2010, doi: 10.1016/j.biopha.2009.03.004.

[9] S. Hosseini, K. Parastouei, and F. Khodaiyan, "Simultaneous extraction optimization and characterization of pectin and phenolics from sour cherry pomace," Int J Biol Macromol, vol. 158, pp. 911-921, Apr 30 2020, doi:

10.1016/j.ijbiomac.2020.04.241.

[10] W. Zhang, F. Xie, X. Lan, S. Gong, and Z. Wang, "Characteristics of pectin from black cherry tomato waste modified by dynamic high-pressure microfluidization," Journal of Food Engineering, vol. 216, pp. 90-97, 2018, doi:

10.1016/j.jfoodeng.2017.07.032.

[11] S. M. Hosseini, S. H. Hoseinifar, M. Mazandarani, H. Paknejad, H. Van Doan, and E. R. El-Haroun, "The potential benefits of orange peels derived pectin on serum and skin mucus immune parameters, antioxidant defence and growth performance in common carp (Cyprinus carpio)," Fish Shellfish Immunol, vol. 103, pp. 1722, Apr 20 2020, doi: 10.1016/j.fsi.2020.04.019.

[12] Y. Jin and N. Yang, "Array-induced voltages assisted extraction of pectin from grapefruit (Citrus paradisi Macf.) peel and its characterization," Int J Biol Macromol, vol. 152, pp. 1205-1212, Jun 1 2020, doi: 10.1016/j.ijbiomac.2019.10.215.

[13] E. H. Cho, H. T. Jung, B. H. Lee, H. S. Kim, J. K. Rhee, and S. H. Yoo, "Green process development for apple-peel pectin production by organic acid extraction," Carbohydr Polym, vol. 204, pp. 97-103, Jan 15 2019, doi: 10.1016/j.carbpol.2018.09.086.
[14] D. L. Su et al., "Efficient extraction and characterization of pectin from orange peel by a combined surfactant and microwave assisted process," Food Chem, vol. 286, pp. 1-7, Jul 15 2019, doi: 10.1016/j.foodchem.2019.01.200.

[15] Y. Guan et al., "Components of heat-treated Helianthus annuus L. pectin inhibit tumor growth and promote immunity in a mouse CT26 tumor model," Journal of Functional Foods, vol. 48, pp. 190-199, 2018, doi: 10.1016/j.jff.2018.07.001.

[16] R. G. Zhu, Y. D. Sun, Y. T. Hou, J. G. Fan, G. Chen, and T. P. Li, "Pectin pentaoligogalacturonide reduces cholesterol accumulation by promoting bile acid biosynthesis and excretion in high-cholesterol-fed mice," Chem Biol Interact, vol. 272, pp. 153-159, Jun 25 2017, doi: 10.1016/j.cbi.2017.05.018.

[17] C. Ramachandran, B. J. Wilk, A. Hotchkiss, H. Chau, I. Eliaz, and S. J. Melnick, "Activation of human T-helper/inducer cell, T-cytotoxic cell, Bcell, and natural killer (NK)-cells and induction of natural killer cell activity against K562 chronic myeloid leukemia cells with modified citrus pectin," BMC Complement Altern Med, vol. 11, p. 59, Aug 4 2011, doi: 10.1186/1472-6882-11-59.

[18] S. M. Sureban et al., "Dietary Pectin Increases Intestinal Crypt Stem Cell Survival following Radiation Injury," PLoS One, vol. 10, no. 8, p. e0135561, 2015, doi:

10.1371/journal.pone.0135561.

[19] J. C. Amorim, L. C. Vriesmann, C. L. Petkowicz, G. R. Martinez, and G. R. Noleto, "Modified pectin from Theobroma cacao induces potent pro-inflammatory activity in murine peritoneal macrophage," Int J Biol Macromol, vol. 92, pp. 1040-1048, Nov 2016, doi: 10.1016/j.ijbiomac.2016.08.015.

[20] I. Eliaz and A. Raz, "Pleiotropic Effects of Modified Citrus Pectin," Nutrients, vol. 11, no. 11, Nov 1 2019, doi: 10.3390/nu11112619.

[21] F. Papaccio, F. Paino, T. Regad, G. Papaccio, V. Desiderio, and V. Tirino, "Concise Review: 
Cancer Cells, Cancer Stem Cells, and

Mesenchymal Stem Cells: Influence in Cancer

Development," Stem Cells Transl Med, vol. 6, no.

12, pp. 2115-2125, Dec 2017, doi:

$10.1002 /$ sctm.17-0138.

[22] M. Prieto-Vila, R. U. Takahashi, W. Usuba, I. Kohama, and T. Ochiya, "Drug Resistance Driven by Cancer Stem Cells and Their Niche," Int J Mol Sci, vol. 18, no. 12, Dec 1 2017, doi: 10.3390/ijms 18122574 .

[23] H. R. Sun et al., "Therapeutic Strategies

Targeting Cancer Stem Cells and Their Microenvironment," Front Oncol, vol. 9, p. 1104, 2019, doi: 10.3389/fonc.2019.01104.

[24] X. H. Liu, C. X. Deng, P. C. Hu, Y. Wang, and Y. H. Dong, "Functional impact of Galectin-3 and TRAIL expression in breast cancer cells," Eur Rev Med Pharmacol Sci, vol. 21, no. 16, pp. 36263633, Aug 2017. [Online]. Available: https://www.ncbi.nlm.nih.gov/pubmed/28925481.

[25] H. Wang et al., "LGALS3 Promotes Treatment Resistance in Glioblastoma and Is Associated with Tumor Risk and Prognosis," Cancer Epidemiol Biomarkers Prev, vol. 28, no. 4, pp. 760-769, Apr 2019, doi: 10.1158/10559965.EPI-18-0638.

[26] E. Jonasson et al., "Identification of Breast Cancer Stem Cell Related Genes Using Functional Cellular Assays Combined With Single-Cell RNA Sequencing in MDA-MB-231 Cells," Front Genet, vol. 10, p. 500, 2019, doi:

10.3389/fgene.2019.00500.

[27] D. Govindaraj, M. Rajan, A. A. Hatamleh, and M. A. Munusamy, "From waste to high-value product: Jackfruit peel derived pectin/apatite bionanocomposites for bone healing applications," Int J Biol Macromol, vol. 106, pp. 293-301, Jan 2018, doi: 10.1016/j.ijbiomac.2017.08.017.

[28] J. Li et al., "Modulation of mesenchymal stem cells behaviors by chitosan/gelatin/pectin network films," J Biomed Mater Res B Appl Biomater, vol.
95, no. 2, pp. 308-19, Nov 2010, doi: 10.1002/jbm.b.31715.

[29] F. Chen et al., "Self-crosslinking and injectable hyaluronic acid/RGD-functionalized pectin hydrogel for cartilage tissue engineering," Carbohydr Polym, vol. 166, pp. 31-44, Jun 15 2017, doi: 10.1016/j.carbpol.2017.02.059.

[30] M. Dziadek, A. Zima, E. Cichoń, J. Czechowska, and A. Ślósarczyk,

"Biomicroconcretes based on the hybrid HAp/CTS granules, $\alpha$-TCP and pectins as a novel injectable bone substitutes," Materials Letters, vol. 265, 2020, doi: 10.1016/j.matlet.2020.127457.

[31] M. Ghorbani, L. Roshangar, and J. Soleimani Rad, "Development of reinforced chitosan/pectin scaffold by using the cellulose nanocrystals as nanofillers: An injectable hydrogel for tissue engineering," European Polymer Journal, vol. 130, 2020, doi: 10.1016/j.eurpolymj.2020.109697.

[32] N. Li et al., "Fabrication and Characterization of Pectin Hydrogel Nanofiber Scaffolds for Differentiation of Mesenchymal Stem Cells into Vascular Cells," ACS Biomaterials Science \& Engineering, vol. 5, no. 12, pp. 6511-6519, 2019, doi: 10.1021/acsbiomaterials.9b01178.

[33] D. Platt and A. Raz, "Modulation of the lung colonization of B16-F1 melanoma cells by citrus pectin," (in eng), J Natl Cancer Inst, vol. 84, no. 6, pp. 438-42, Mar 18 1992, doi:

10.1093/jnci/84.6.438.

[34] G. Päth, N. Perakakis, C. S. Mantzoros, and J. Seufert, "Stem cells in the treatment of diabetes mellitus - Focus on mesenchymal stem cells," Metabolism, vol. 90, pp. 1-15, 2019, doi: 10.1016/j.metabol.2018.10.005.

[35] D. T. Chu et al., "Adipose Tissue Stem Cells for Therapy: An Update on the Progress of Isolation, Culture, Storage, and Clinical Application," J Clin Med, vol. 8, no. 7, Jun 26 2019, doi: 10.3390/jcm8070917. 
[36] S. Morikawa et al., "Applications of Mesenchymal Stem Cells and Neural Crest Cells in Craniofacial Skeletal Research," Stem Cells Int, vol. 2016, p. 2849879, 2016, doi: $10.1155 / 2016 / 2849879$.

[37] S. C. Neves et al., "Biofunctionalized pectin hydrogels as 3D cellular microenvironments," J Mater Chem B, vol. 3, no. 10, pp. 2096-2108, Mar 14 2015, doi: 10.1039/c4tb00885e.

[38] A. Polymeri, W. V. Giannobile, and D. Kaigler, "Bone Marrow Stromal Stem Cells in Tissue Engineering and Regenerative Medicine," Horm Metab Res, vol. 48, no. 11, pp. 700-713, Nov 2016, doi: 10.1055/s-0042-118458.

[39] A. R. Silini et al., "Immunological and Differentiation Properties of Amniotic Cells Are Retained After Immobilization in Pectin Gel," Cell Transplant, vol. 27, no. 1, pp. 70-76, Jan 2018, doi: $10.1177 / 0963689717738786$.

[40] J. G. Martins, S. E. A. Camargo, T. T. Bishop, K. C. Popat, M. J. Kipper, and A. F. Martins, "Pectin-chitosan membrane scaffold imparts controlled stem cell adhesion and proliferation," Carbohydr Polym, vol. 197, pp. 47-56, Oct 1 2018, doi: 10.1016/j.carbpol.2018.05.062.

[41] F. Ahadi, S. Khorshidi, and A. Karkhaneh, "A hydrogel/fiber scaffold based on silk

fibroin/oxidized pectin with sustainable release of vancomycin hydrochloride," European Polymer Journal, vol. 118, pp. 265-274, 2019, doi:

10.1016/j.eurpolymj.2019.06.001.

[42] Y. Komada et al., "Origins and properties of dental, thymic, and bone marrow mesenchymal cells and their stem cells," PLoS One, vol. 7, no. 11, p. e46436, 2012, doi: 10.1371/journal.pone.0046436.

[43] E. Anitua, M. Troya, and M. Zalduendo, "Progress in the use of dental pulp stem cells in regenerative medicine," Cytotherapy, vol. 20, no. 4, pp. 479-498, Apr 2018, doi: 10.1016/j.jcyt.2017.12.011.
[44] M. La Noce et al., "Dental pulp stem cells: state of the art and suggestions for a true translation of research into therapy," J Dent, vol. 42, no. 7, pp. 761-8, Jul 2014, doi: 10.1016/j.jdent.2014.02.018.

[45] M. C. Yurtsever, A. Kiremitci, and M. Gumusderelioglu, "Dopaminergic induction of human dental pulp stem cells by photobiomodulation: comparison of $660 \mathrm{~nm}$ laser light and polychromatic light in the nir," $\mathrm{J}$ Photochem Photobiol B, vol. 204, p. 111742, Mar 2020, doi: 10.1016/j.jphotobiol.2019.111742.

[46] L. Leclere, P. V. Cutsem, and C. Michiels, "Anti-cancer activities of $\mathrm{pH}$ - or heat-modified pectin," Front Pharmacol, vol. 4, p. 128, Oct 8 2013, doi: 10.3389/fphar.2013.00128.

[47] W. Zhang, P. Xu, and H. Zhang, "Pectin in cancer therapy: A review," Trends in Food Science \& Technology, vol. 44, no. 2, pp. 258-271, 2015, doi: 10.1016/j.tifs.2015.04.001.

[48] E. M. Czekanska, "Assessment of cell proliferation with resazurin-based fluorescent dye," (in eng), Methods Mol Biol, vol. 740, pp. 2732, 2011, doi: 10.1007/978-1-61779-108-6_5.

[49] F. Asghari Sana, M. Capkin Yurtsever, G. Kaynak Bayrak, E. O. Tuncay, A. S. Kiremitci, and M. Gumusderelioglu, "Spreading, proliferation and differentiation of human dental pulp stem cells on chitosan scaffolds immobilized with RGD or fibronectin," Cytotechnology, vol. 69, no. 4, pp. 617-630, Aug 2017, doi: 10.1007/s10616-0170072-9.

[50] L. Leclere et al., "Heat-modified citrus pectin induces apoptosis-like cell death and autophagy in HepG2 and A549 cancer cells," PLoS One, vol. 10, no. 3, p. e0115831, 2015, doi: 10.1371/journal.pone.0115831.

[51] V. Hawach, Abdel-Massih, R. M., Boujaoude, M., "The Cytotoxic and Anti-proliferative Activity of High Molecular Weight Pectin and Modified Citrus Pectin," Functional Foods in Health and Disease, vol. 6, pp. 587-601, 2016. 
[52] M. Kressel and P. Groscurth, "Distinction of apoptotic and necrotic cell death by in situ labelling of fragmented DNA," (in eng), Cell Tissue Res, vol. 278, no. 3, pp. 549-56, Dec 1994, doi: 10.1007/bf00331373.

[53] H. Inohara and A. Raz, "Effects of natural complex carbohydrate (citrus pectin) on murine melanoma cell properties related to galectin-3 functions," Glycoconj J, vol. 11, no. 6, pp. 527-32, Dec 1994, doi: 10.1007/BF00731303.

[54] C. L. Jackson et al., "Pectin induces apoptosis in human prostate cancer cells: correlation of apoptotic function with pectin structure," Glycobiology, vol. 17, no. 8, pp. 805-19, Aug 2007, doi: 10.1093/glycob/cwm054.

[55] F. O. Ogutu, T. H. Mu, H. Sun, and M. Zhang, "Ultrasonic Modified Sweet Potato Pectin Induces Apoptosis like Cell Death in Colon Cancer (HT-29) Cell Line," Nutr Cancer, vol. 70, no. 1, pp. 136-145, Jan 2018, doi:

10.1080/01635581.2018.1406123.

[56] M. Sioud, A. Mobergslien, A. Boudabous, and Y. Floisand, "Evidence for the involvement of galectin-3 in mesenchymal stem cell suppression of allogeneic T-cell proliferation," Scand J Immunol, vol. 71, no. 4, pp. 267-74, Apr 2010, doi: 10.1111/j.1365-3083.2010.02378.x.

[57] U. V. Sathisha, S. Jayaram, M. A. Harish Nayaka, and S. M. Dharmesh, "Inhibition of galectin-3 mediated cellular interactions by pectic polysaccharides from dietary sources," Glycoconj J, vol. 24, no. 8, pp. 497-507, Nov 2007, doi: 10.1007/s10719-007-9042-3.

[58] T. Zhang et al., "Multiple approaches to assess pectin binding to galectin-3," Int J Biol Macromol, vol. 91, pp. 994-1001, Oct 2016, doi: 10.1016/j.ijbiomac.2016.06.058. 